\title{
"VENDER ALGUMA COISA, DAR CERTO NA VIDA". A PASSAgem do POEMA AO OBJETO NA OBRA DE MARCEL BROODTHAERS
}

\author{
Eduardo Jorge de Oliveira
}

Para Sérgio Bessa

\section{SILENCIAR O POETA, ACORDAR O ARTISTA}

Artista dos artistas, curador dos curadores. Assim Marcel Broodthaers (1924-1976) foi definido na página de abertura do catálogo da retrospectiva da sua obra no MoMa, em Nova Iorque, de 14 de fevereiro a 15 de março de 2016. A exposição, com curadoria de Manuel Borja-Villel e Christophe Cherix (2016), resume, assim, o reconhecimento vindo de uma das maiores instituições do campo artístico. Nascido na Bélgica em 1924, Broodthears publicou os livros de poemas Mon livre d'ogre [Meu livro de ogro], em 1957, Minuit [Meia-noite], em 1960, além do volume intitulado Pensebête [Lembrete], em 1964. Com pouca circulação, seus livros se tornaram mais conhecidos posteriormente no espaço expositivo, quando o autor mudou de estatuto, passando a artista, o que fez com que seus poemas e textos enunciassem uma poética encontrada nos seus museus inventados, nos seus departamentos imaginados, encontrando na realização de tais espaços outro nível de materialidade para os poemas.

Seriam os poemas um elemento de ligação das práticas artísticas de Marcel Broodthears? Pense-bête, por exemplo, é um livro que se tornou objeto de anedota, pois ele seria o marco da passagem do poeta ao artista, 
quando exposto na Galeria Saint Laurent, em abril de 1964, em Bruxelas, sob o título Moi aussi, je me suis demandé si je ne pouvais pas vendre quelque chose et réussir dans la vie [Eu também me perguntei se não podia vender algo e dar certo na vida]. Fazer do livro um objeto, ou melhor, uma escultura, marcou a iniciação de Broodthears no circuito comercial das galerias, fato controverso, pois talvez ele não tenha obtido o retorno material com a carreira de artista. Entretanto, pelo viés da organização dos objetos, dos livros, o artista criou um lugar para o poema dentro do espaço da galeria, provocando, assim, uma passagem do poema ao objeto através do ocultamento semântico do primeiro. A descrição do procedimento do artista foi brevemente apresentada em um de seus poemas posteriores a seus livros. Em Marcel Broodthaers - moule, muse, méduse, Jean-Philippe Antoine (2006, p. 7) reproduz o texto integral do convite:

[... Cela fait un moment déjà que je ne suis bon à rien. Je suis âgé de quarante ans...

L'idée enfin d'inventer quelque chose d'insincère me traversa l'esprit

Et je me mis aussitôt au travail. Au bout de trois mois, je montrai ma

Production à Ph. Edouard Touissant le propriétaire de la Galerie Saint-Laurent.

Mais c'est de l'art, dit-il, et j'exposerais volontiers tout ça.

D’accord, lui répondis-je.

$\mathrm{Si}$ je vends quelque chose il prendra $30 \%$,

Ce sont paraît-il des conditions normales

Certaines galeries prenant $75 \%$.

Ce que c'est?

En fait, des objets. ${ }^{1}$

O modo de nomear o livro como "objeto" retira tanto a mais anódina quanto a mais importante função do poema através da leitura. Com os poemas parcialmente cobertos por pedaços coloridos de papel em livros abertos e com outros exemplares fechados, o material se inscreve em um sistema artístico dos objetos. A entrada dele na economia da arte comercial implica um tipo de renúncia do próprio livro como objeto de circulação destinado à leitura, mesmo que esta seja restrita. Além da exposição dos livros com "lembretes" das mais diversas cores colados sobre os poemas,

\footnotetext{
1 "Já faz um tempo que não sirvo para nada. Eu tenho quarenta anos de idade... A ideia de inventar algo de insincero me veio à cabeça e me pus imediatamente a trabalhar. Depois de três meses, mostrei minha produção a Ph. Edouard Touissant, o proprietário da Galeria Saint-Laurent. Mas é arte, ele disse, e eu exporia de boa vontade tudo isso. Estou de acordo, respondi. Se eu vender algo, ele ficará com 30\%. São as condições normais, ao que parece. Algumas galerias levam $75 \%$. O que é? Na verdade, objetos." Todas as traduções são nossas, salvo quando estiverem indicadas.
}

Remate de Males, Campinas-SP, v. 37 n. 1, pp. 261-284, jan./jun. 2017 
parte da tiragem de Pense-bête serviu de base para uma escultura (figura 1).

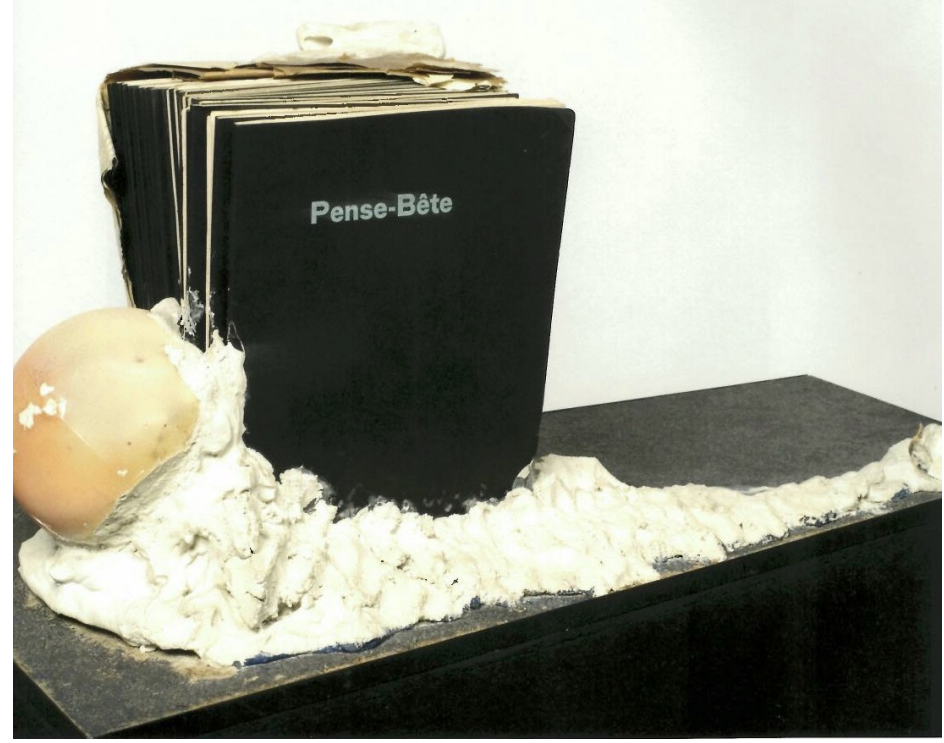

Figura 1. Pense-Bête, escultura de Marcel Broodthaers (1964).

Fonte: Borja-Villel e Cherix (2016).

Jean-Philippe Antoine (2006, p. 11) associa duas ações com o mesmo livro ligadas a essa iniciação às artes visuais: a primeira seria um ato deliberado da interdição da leitura e, a segunda, a produção material de um objeto, a concretização da própria escultura. Esse foi o começo da vida de artista que, segundo Benjamin Buchloh (2016, p. 42), termina prematuramente, em 1974, com outra obra, La conquête de l'espace, atlas à l'usage des artistes et militaires [A conquista do espaço, atlas para uso de artistas e militares] (Borja-Villel; Cherix, 2016). O atlas em questão é um pequeno livro que cabe na palma da mão, do tamanho de uma caixa de fósforos. O livro aberto existe apenas como uma folha na dimensão de 50,5 cm x 69,5 cm, apresentando os mapas de trinta e dois países, igualados em termos de escala e diferenciados apenas pelo desenho do território (Figura 2). 


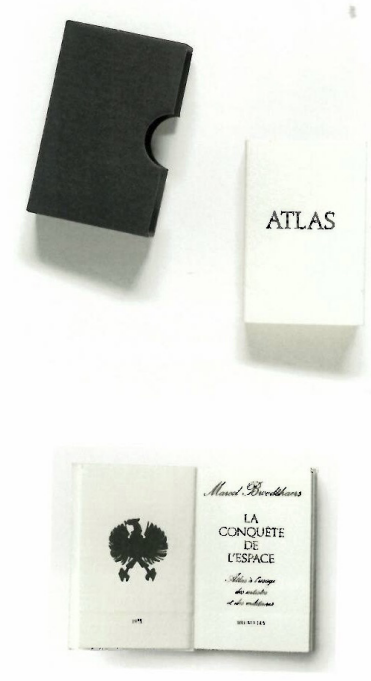

Figura 2. Foto do livro La conquête de l'espace.

Fonte: Borja-Villel e Cherix (2016).

Entre os livros de poemas que se tornam objetos e o atlas, Broodthears alterou os livros de outros poetas, valendo-se deles como um material elementar de composição para suas obras. De Charles Baudelaire a Stéphane Mallarmé, o artista elabora para cada um deles um objeto, seja ele um filme ou uma exposição. Baudelaire "assina" um dos filmes de Broodthears, em 1970, sendo também título de uma de suas obras, em 1973, Charles Baudelaire. Je hais le mouvement qui déplace les lignes [Eu odeio o movimento que desloca as linhas]. Mallarmé torna-se, no final de 1969, objeto de uma exposição literária, organizada pelo próprio Marcel Broodthaers.

O termo "exposição literária" marca, no final dos anos sessenta, a passagem da literatura para o museu, uma migração que possui uma base estética e econômica, assinalada pela ausência de finalidade do poeta que "não serve para nada" [ne sert à rien] - em oposição ao artista - que produz objetos e os dispõe à venda em uma galeria. Assim, ao trocar de estatuto ele passa de poeta a artista, assumindo, inclusive, o papel de "organizador de exposições", como havia nomeado a atividade Harald 
Szeemann (BEZZOLA; KURZMEYER, 2007), no final dos anos cinquenta, antecedendo a instituição da atividade econômica de curadoria de exposições. Broodthaers tornou-se, assim, um artista de referência como organizador de obras-exposições, criador de coleções, apropriandose de um vocabulário burocrático dos museus, que estava em pleno nascimento. Essa prática pode ser identificada, por um lado, como um dos procedimentos de desvalorização da literatura e, por outro, como um modo de fazer com que os signos literários circulem materialmente dentro das regras de galerias e museus.

\section{O MOdelo M: DE MAllarmé AO MUSEU OU O RENASCIMENTO DO ARTISTA}

O primeiro aspecto - o da história da desvalorização da literatura -, foi tratado por William Marx e constituiu para o século XX um momento decisivo, mesmo que a desvalorização da literatura tenha sido situada por ele como iniciada a partir do século XVIII, quando uma multiplicidade de cronologias envolvendo catástrofes e desastres se prolongara na linguagem. O que merece ser destacado no quadro histórico brevemente apresentado por ele é a figura emblemática da "desistência" da poesia em Arthur Rimbaud e a fundação da modernidade poética com Un coup de dés (1897) até chegar aos silêncios de Monsieur Teste, de Paul Valéry (MARX, 2005). O segundo aspecto, anterior a Broodthaers e que merece atenção, é a presença de Marcel Duchamp, especificamente a linguagem travestida de Rrose Sélavy, em que existe uma ressonância direta com o artista belga. A noção de ready-made aparece no primeiro fragmento de Rrose Sélavy, e ela depende dos "achados" da linguagem a partir da materialidade da língua: "Rrose Sélavy trouve qu'un incesticide doit coucher avec la mère avant de la tuer; les punaises sont de rigueur" (DUCHAMP, 1939, [s.p.]).²

Nos Collected writings, de Broodthaers (2012), organizado por Gloria Moure, existe uma breve ficção com a letra M, em "A Throw of the Dice" [Um lande de dados], de 1969. O peso e a duração seriam funções da letra advindas da consciência da tipografia. A letra $M$, nesse sentido, torna-se índice móvel para uma sequência que o artista cria, a começar pela música. Na segunda parte do texto "Theory", a letra M indicaria a "poesia como a fonte", onde a sequência que nomeia a peça, "A throw of the dice", ressalta

2 "Rrose Sélavy acha que um incesticida deve dormir com a mãe antes de matá-la; os percevejos são duros.”

Remate de Males, Campinas-SP, v. 37 n. 1, pp. 261-284, jan./jun. 2017 
a importância de Leonardo da Vinci (sobre quem Paul Valéry escreveu um "método") e sua relação com os Médicis (BROODTHAERS, 2012). A partir de uma letra precisa, "M", Broodthaers formula uma das questões centrais na sua obra, e ela funciona como um ponto central para o estudo da passagem material da literatura para os museus: "is there negotiation or montage between the word and its image? between the idea and its $M$. theatre?" (pp. 238-239). 3 A oscilação presente desde o momento em que o poeta desiste dos seus livros e se submete ao sistema de uma galeria de arte para a venda dos objetos se concentra na dinâmica de negociação e de montagem entre a palavra e sua imagem. O pronome possessivo "seu" confere à imagem um pertencimento. E o artista, para chegar ao museu, necessita de um modelo:

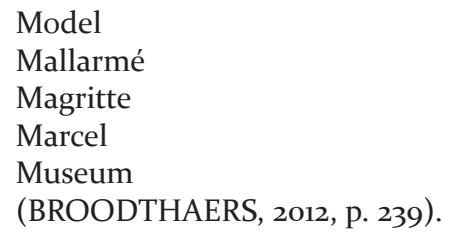

Model

Mallarmé

Magritte

Marcel

Museum

(BROODTHAERS, 2012, p. 239).

Trata-se de uma relação com o espaço literário, onde a imagem da palavra ecoa em um espaço posterior ao livro, já delimitado por Mallarmé. Em “Variations sur um sujet”, precisamente em “Quant au livre”, Mallarmé (1945, p. 369) escreve:

Agir, sans ceci et pour qui n'en fait commencer l'exercice à fumer, signifia, visiteur, je te comprends, philosophiquement, produire sur beaucoup un mouvement qui te donne en retour sur l'émoi que tu en fus le principe, donc existes: dont aucun ne se croit, au préalable, sûr. Cette pratique entend deux façons ; ou, par une volonté, à l'insu, qui dure une vie, jusqu'à l'éclat multiple - penser, cela: sinon, les déversoirs à portée maintenant dans une prévoyance, journaux et leur tourbillon, y déterminer une force en un sens, quelconque de divers contrariée, avec l'immunité du résultat nul. ${ }^{4}$

\footnotetext{
3 "Seria isso negociação ou montagem entre a palavra e a sua imagem? Entre a ideia e o seu M. teatro?"

4 Tradução nossa, em conjunto com Loïck Lemesle: "Agir, sem isto e para quem não inicia o exercício de fumar, significou, visitante, eu te entendo, filosoficamente, produzir sobre muitos um movimento que te dê de volta a emoção de que tu fostes o princípio, logo existes: do que ninguém se crê previamente seguro. Essa prática compreende duas formas: ou, por uma vontade, não sabida, que dura uma vida, até o estouro múltiplo pensar, isso; senão, os mananciais ao alcance agora em uma previdência, jornais e seu turbilhão, determinando uma força em um sentido qualquer por diversos contrariada, com a imunidade do resultado nulo".
}

Remate de Males, Campinas-SP, v. 37 n. 1, pp. 261-284, jan./jun. 2017 
A primeira palavra é uma ação: agir. Nessa ação existe em potência o resultado nulo, e será esta potência a fonte de uma imunidade. Marcel Broodthaers parece ter feito um esforço programático para produzir, sobretudo, um movimento que cria traços, e tais traços são letras. Sua ação é praticamente tipográfica, serial, serigráfica. O que ele faz é estabelecer a sua tradição entre o modelo e o museu. A construção de tal tradição enfatiza as palavras do poeta inglês T. S. Eliot, em que "tradition is a matter of much wider significance. It cannot be inherited, and if you want it you must obtain it by great labor" (ELIOT, 1982, p. 37). ${ }^{5}$ Talvez, ao longo de uma abstinência de livros de poemas, o artista tenha construído poeticamente sua tradição, de Mallarmé a Marcel Duchamp, passando por Magritte até chegar ao museu. O modelo Museu de Broodthaers é, portanto, a literatura, mais precisamente, a expansão da falha como poeta que, por um lado, lida com um nível preciso da linguagem e, por outro, mantém-se em uma "ação restrita”. Assim, a experiência literária do artista atinge algumas galerias, e as obras, os museus ou departamentos dele acabaram por tornar-se modelos que tiveram um raio de circulação tão restrito quanto o de sua poesia.

O fato de uma grande retrospectiva ser dedicada ao artista no MoMa, em Nova Iorque, e no Museu Reina Sofía, em Madrid, faz com que sua obra tenha uma circulação expandida, atingindo oápice dos espaços expositivos em dois grandes museus. No entanto, a obra Museal, de Broodthaers, não deixa de afirmar o que o próprio Brian O’Doherty (2002, p. 4) escreveu a propósito desses espaços, também conhecidos por "Cubo branco", o que inclui o próprio MoMa:

A galeria é construída de acordo com preceitos tão rigorosos quanto os da construção de uma igreja medieval. O mundo exterior não deve entrar, de modo que as janelas geralmente são lacradas. As paredes são pintadas de branco. O teto torna-se a fonte de luz. O chão de madeira é polido, para que você provoque estalidos austeros ao andar, ou acarpetado, para que você ande sem ruído. A arte é livre, como se dizia "para assumir vida própria". Uma mesa discreta talvez seja a única mobília. Nesse ambiente, um cinzeiro de pé torna-se quase um objeto sagrado, da mesma maneira que uma mangueira de incêndio num museu moderno não se parece com uma mangueira de incêndio, mas com uma charada artística. Completa-se a transposição modernista da percepção, da vida para os valores formais. Esta, claro, é uma das doenças fatais do modernismo.

5 “[...] tradição tem um amplo significado. Ela não pode ser herdada e se você a deseja, você precisa obtê-la com um grande esforço".

Remate de Males, Campinas-SP, v. 37 n. 1, pp. 261-284, jan./jun. 2017 
As observações de O’Doerty retratam que o objeto artístico, para ser vendável ou, no mínimo, ser observado, necessitou de uma construção de sentido que sacraliza e ironiza o modo de expor obras em um espaço neutro. Mesmo a ironia tornou-se objeto de sacralização. No ambiente do cubo branco as obras, enfim, isoladas, podem ser contempladas sem a interferência de um elemento exterior à própria realidade da obra. A neutralidade desse espaço não deixa de ser contestada pelos próprios artistas ao longo dos anos sessenta e setenta, o que inclui as obras de Broodthaers. A exposição que o artista organizou a partir de Mallarmé não contesta, todavia, o espaço em questão. Em outro fragmento de "Quant au livre", de Mallarmé, o poeta menciona um alfabeto de astros: "tu remarquas, on n'écrit pas, lumineusement, sur champ obscur, l'alphabet des astres, seul, ainsi s'indique, ébauché ou interrompu; l'homme poursuit noir sur blanc" (MALLARMÉ, 1945, p. 370). ${ }^{6}$ Em um primeiro momento, a exposição literária torna-se frágil, diante das realizações e do inacabamento em Mallarmé, para citar, de um lado, Un coup de dés e, de outro, a concepção que o poeta tinha de livro. Broodthaers, todavia, buscava a conquista do espaço. Essa conquista não seria feita sem os elementos literários e a simultaneidade da sacralização e da ironia do livro como objeto. Mallarmé é fundamental para que Marcel Broodthaers chegue ao museu. Os objetos da exposição literária seguem praticamente a indicação rigorosa de uma página impressa, preto e branco. Há uma pintura, todavia, em que a precisão do preto e do branco escapa. Trata-se de Un coup de dés jamais quand bien même [Um lance de dados mesmo assim], de 1969 (Figura 3).

6 Em traduçãoconjunta com Loïck Lemesle: "Tu observarás, não seescreve, luminosamente, no campo escuro, o alfabeto dos astros, só, assim se indica, esboçado ou interrompido; o homem persegue preto sobre branco". 


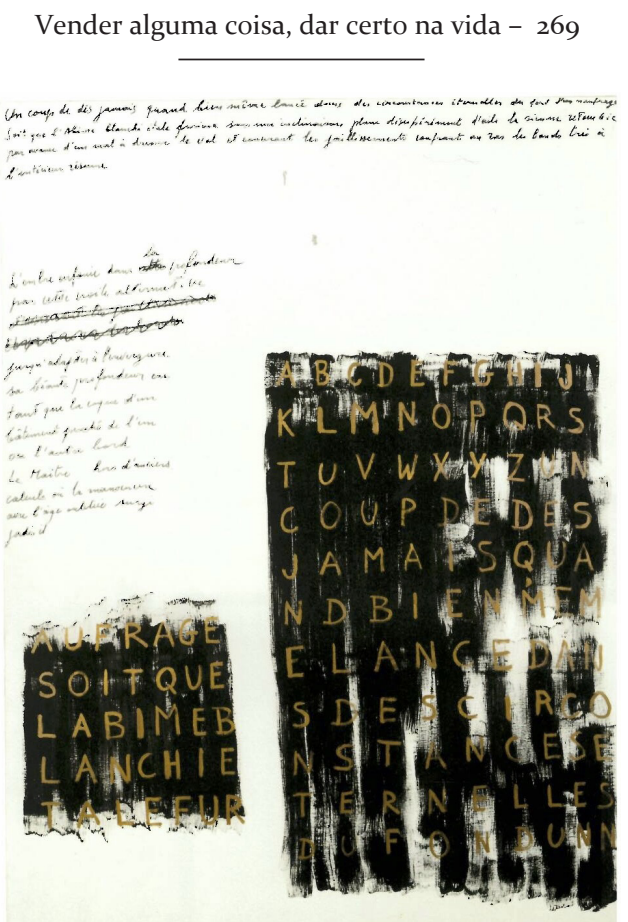

Figura 3. Un coup de dés jamais quand bien même (BROODTHAERS, 1969).

Fonte: Borja-Villel e Cherix (2016).

Na tela está pintado o alfabeto, fragmentos de palavras ligadas à ideia de naufrágio e duas partes manuscritas, onde o topos de Un coup de dés marca o espaço da poesia moderna.

Retornando à exposição dedicada a Mallarmé, como poderia ser delimitada a presença de elementos literários em uma galeria de arte? $\mathrm{O}$ procedimento que o artista fez em relação aos próprios livros se repete: ocultamento dos versos e elaboração de objetos. Em relação à exposição, o convite, no formato de um cartão postal, traz o retrato do poeta feito por Nadar, e, ao lado, há um selo belga com o carimbo dos correios. Na segunda exposição, realizada em 1970, ele acrescenta "musical" ao "literário", realizando uma mostra literária e musical, além de um "mapa poético do mundo". Este é uma reprodução do mapa-múndi e, acima dele, Broodthaers rasura o político, de "mapa político do mundo", acrescentando apenas "poético".

Jacques Rancière (2005), em L'espace des mots - de Mallarmé à Broodthaers, recupera o argumento de Paul Valéry a partir de Un coup de dés, ao afirmar que o artista, ao apagar os versos do poema, mostrou que a "área falava". Para contextualizar a disposição entre Valéry-Mallarmé- 
Broodthaers, é preciso descrever brevemente uma das obras da exposição. Ela consiste na apropriação que o artista faz do célebre poema de Mallarmé "Un coup de dés jamais n’abolira le hasard". Em uma litogravura que simula a edição da Gallimard, o nome Mallarmé é substituído por Broodthaers e logo abaixo do título do poema lê-se a palavra "image". Em doze placas nas dimensões 32,4 X 49,7 x 0,3 cm, a reprodução de cada página do poema de Mallarmé apresenta os versos em retângulos negros, como a indicar onde antes estavam os versos. A obra de Broodthaers pode ser vista como uma crítica ao que é mais vital no poema: toda a cadeia sintático-semântica negada por ele quando se tornou "artista". Restaria, todavia, um tipo de hermetismo esquivo, afirmado pelo ocultamento da leitura do poema ou pelo desaparecimento dos versos. Jacques Rancière (2005, pp. 7-8) é reticente quanto ao procedimento:

\begin{abstract}
Broodthaers afirma o poder que as palavras têm para criar espaços. Ora, o uso que ele faz do poema de Mallarmé parece contradizer esse princípio porque ele separou precisamente as palavras das imagens. De um lado ele reproduziu em uma página dupla o texto do poema em uma continuidade que foi cortada apenas pelas barras oblíquas que simbolizavam as passagens para a linha. Por outro lado, ele reproduziu a disposição espacial sem as palavras. Ele apagou as palavras em proveito de um equivalente plástico que lhes comunique a identidade indiferente do espaço ampliado.
\end{abstract}

O termo que possivelmente resumiria a operação do artista identificada por Rancière seria modulação. Sob os moldes do cubo branco, o artista marcou apenas a intensidade e o ritmo do poema por meio de retângulos negros que cobrem os versos do poema. Em um primeiro momento, a consciência do branco da página encontra a "brancura" do espaço expositivo, embora permaneça um conflito entre escrita e exposição presente na obra de Broodthaers. A contribuição dele - que assim resolve temporariamente o conflito - é o cruzamento entre a própria ideia de fábula e a noção romana de genius loci, o "espírito do lugar" adequado ao espaço expositivo, pois, em detrimento da neutralidade do cubo branco, o artista com seu museu conseguiu, finalmente, criar uma fábula a partir de um espaço específico. Antes dessa obra com Mallarmé, Broodthaers havia dedicado uma exposição à fábula de La Fontaine, "Le corbeau et le renard" [O corvo e a raposa], em 1968.

Esse texto se tornou a fonte para um filme realizado pelo artista entre maio e outubro de 1967. O branco tem aí um papel decisivo, os objetos estão impregnados por ele, que marca o contraste necessário com o texto. Além de objetos brancos e garrafas transparentes, existem aparelhos telefônicos 
e uma bota, ambos negros. A cor existe, em contraste, apenas em um vaso com flores. Ao longo do filme o artista exibe fragmentos de sua coleção ou do seu museu, atravessados pela palavra-chave da fábula de La Fontaine: queijo. ${ }^{7} \mathrm{O}$ texto aparece apenas parcialmente. Além do filme, existe uma instalação feita com uma máquina de datilografar, na qual a fábula, ao invés de datiloscrita, aparece manuscrita, acrescida da silhueta do artista escrevendo o texto de La Fontaine (BROODTHAERS, 1968). No espaço entre o filme e a instalação, Broodthaers preparou uma caixa branca com tiragem de 40 exemplares, nos quais o texto está impresso por dentro e por fora. No fundo da caixa, logo abaixo do texto, está a reprodução de fotografias de objetos, um ovo, uma garrafa e dois pratos com fritas. Foi com esse espírito de cruzar a fábula com o genius loci do museu que o artista iniciava o que ele chamou de "conquista do espaço".

Na obra de 1974, Atlas, Marcel Broodthaers deixa claro o objetivo de uma "conquista do espaço". Como observa Gloria Moure (2012, p. 16), "the Conquête de l'espace implies a space of writing, a true artistic genre intrinsically linked to the concept of 'décor', which has far-reaching aesthetic implications in Broodthaers's work". Essa conquista inclui o espaço da escrita, e o que pode ser interrogado a partir dela é o tipo de política que o artista aciona. A política não estaria tão distante da conquista de Mallarmé na consensual afirmação da recepção crítica do poema, em que a página havia adquirido a potência de um céu estrelado.

Em 1964, Maurice Blanchot havia redigido um artigo para a revista italiana Il Menabo, em Turim, intitulado "La conquête de l'espace" [A conquista do espaço]. O breve artigo, que foi republicado nos Écrits politiques, trata do astronauta russo Iuri Gagarin e sua viagem fora da Terra como um modo de consideração do "nomadismo da verdade". Isso significa, para Blanchot (2008), que o antigo céu das religiões e das contemplações, agora desfeito de sua pureza e de sua sublimidade tornouse cálculo e libertação do próprio espaço. O que ele resume com Gagarin é que cada homem se tornou um pouco este homem do Fora, rompendo, desse modo, com a fixidez do lugar.

7 Na fábula "Le courbeau et le renard", a raposa cobiça o pedaço de queijo no bico do corvo e, ao elogiar suas plumas, pergunta se ele poderia cantar. Envaidecido pelo elogio, o corvo canta e perde seu pedaço de queijo.

8 "[...] a Conquista do espaço implica um espaço de escrita, o verdadeiro gênero artístico que está intrinsicamente ligado ao conceito de 'decoro', que abrangeu implicações estéticas na obra de Broodthaers".

Remate de Males, Campinas-SP, v. 37 n. 1, pp. 261-284, jan./jun. 2017 
A conquista do espaço destinada para militares e artistas, como havia afirmado Broodthaers, incorpora um tom político semelhante à busca de outro espaço para a escrita, situado, no seu Atlas, entre Mallarmé e Blanchot. Assim, Marcel Broodthaers não abandona apenas a sua produção poética, mas se apropria de outras obras literárias, mais precisamente de autores poetas, transportando-os para o espaço do Museu. Este, todavia, ainda não se refere à instituição em si, mas a um modo como esse artista agrupa e nomeia suas obras a partir da lógica dos vocábulos "Museu", "Departamento", "Coleção" ou "Catálogo".

Um dos pontos que precisa ser discutido é o motivo pelo qual os textos precisaram ficar ilegíveis e os livros, fechados ou parafraseados ao lado de uma organização deliberada de um "museu" fundado pelo artista em 1968: "Museu de Arte Moderna, Departamento das Águias”. O museu existiu por quatro anos e cada apresentação temporária ganhou o nome de "seção": 1) Seção do Século XIX; 2) Seção Documentário; 3) Seção do SéculoXVII; 4) Seção Literária; 5) Seção do SéculoXIX; 6) Seção Folclórica/ Gabinete de Curiosidades; 7) Seção Cinema; 8) Seção Financeira/ Museu de Arte Moderna à venda por causa de falência; 9) Seção das Figuras; 10) Seção Publicidade; 11) Museu de Arte Moderna; 12) Museu de Arte Antiga, Galeria do Século XX (BORJA-VILLEL; CHERIX, 2016, pp. 174-175).

Inaugurado no dia 29 de setembro de 1968, o museu ficcional de Marcel Broodthaers tinha um objetivo que pode ser resumido em uma questão posta pelo artista no dia da inauguração: "Quais são as novas relações que ligam o artista à sociedade?" (apud BORJA-VILLEL; CHERIX, 2016, p. 178). Em um primeiro momento, a pergunta praticamente imbuída de efeito retórico talvez tenha sido o motivo pelo qual ele tenha mudado de economia - da poesia à arte - para, do interior do próprio sistema artístico lançar a questão não apenas em termos literários, mas no modo de nomear-se diretor ou burocrata da arte. Nas suas seções, cartões-postais com reproduções de obras ao lado de caixas de madeira fechadas ocupam o espaço de uma galeria, enquanto a inscrição "Musée d’Art Moderne section XIX siècle" é utilizada nas reproduções ou nos papéis timbrados das cartas da seção literária que, não sem um senso de humor, reproduz uma frase-chave para René Magritte e para Michel Foucault: "Ceci n'est pas un pipe" [Isto não é um cachimbo]. Na seção de figuras, o artista dispôs das mais diversas representações da águia, animal fortemente ligado à representação militar, às culturas ancestrais, às árvores genealógicas ou mesmo a produtos dispostos à venda no mercado por intermédio de 
anúncios publicitários. O museu de Marcel Broodthaers, no entanto, declara falência, mesmo que uma das águias apareça, em baixo relevo, sobre uma barra de ouro que faz parte do acervo do museu. No folheto que anuncia a venda feita pelo Museu, a literatura está permanentemente em exposição pela falha do poeta e pela falência do museu; em um segundo momento os autores estão expostos em uma lista que começa por Charles Baudelaire, passando por Victor Hugo, Edgar Allan Poe, Kurt Schwitters ou Jonathan Swift.

Depois que o Museu decreta falência, Broodthaers torna-se novamente artista, como ele escreve em 1972, como se a carreira tivesse sido interrompida.

Je suis né em 1924 .

Je deviens artiste em 1963.

J'ai fondé um musée (le Musée d'Art

Moderne, Département des Aigles) em 1968.

Je ferme ce musée em 1972 à la Documenta de

Cassel. La même année je redeviens artiste

(BROODTHAERS apud BORJA-VILLEL; CHERIX, 2016, p. 215). ${ }^{9}$

Mesmo que o artista tenha silenciado o poeta, a experiência do poema persiste em obra, pois o breve texto que poderia ser chamado de poema parece existir pela negatividade da poesia. Existe uma diferença material na passagem dos signos literários ao espaço expositivo, no modo de classificação que difere do das bibliotecas ou de estudos, capazes de considerar diacronicamente comentários e leituras prévias de cada autor listado pelo artista. O uso deliberado do nome de um escritor, de fragmentos de textos, de retratos cria um regime de temporalidade distinto, a partir da leitura feita por um artista. Ela não obedece aos modelos e às formas das instituições literárias, pois segue as indicações dos poetas. Seriam provavelmente essas mesmas leituras situadas em outro ritmo, submissas a outras condições e contradições - a do atelier, a da galeria, a do museu, a da produção e circulação de imagens, por exemplo - que produziriam um tipo de desamparo em relação à compreensão de um autor, de uma obra ou de um período literário. A repercussão da palavra desperta a atenção para a materialidade da literatura nos espaços expositivos. Marcel Broodthaers

9 "Eu nasci em 1924. Me tornei artista em 1963. Fundei um museu (o Museu de Arte Moderna, Departamento das Águias) em 1968. Fechei esse museu em 1972 na Documenta de Kassel. No mesmo ano tornei-me artista de novo."

Remate de Males, Campinas-SP, v. 37 n. 1, pp. 261-284, jan./jun. 2017 
inventou um espaço onde se cruza "a arte da poesia" com a "teoria geral da arte e da coleção".

\section{A ARTE DA POESIA DIANTE DA TEORIA GERAL DA ARTE E DA COLEÇÃO: MARCEL BROODTHAERS E A CONQUISTA DO DECORO}

Aucun homme de loi ne se targue de déloger l'intrus - baux tacites, usages locaux établi par surprise et ayant même payé aux propriétaires: je dois jouer le rôle ou restreindre, à mes droits, l'empiètement.

(Stéphane Mallarmé, 1945, p. 356) ${ }^{10}$

Marcel Broodthaers se insere na herança de Marcel Duchamp, Joseph Beuys e Andy Warhol, ao mesmo tempo em que existe nele uma afinidade eletiva com Daniel Spoerri, Robert Filliou e Joan Brossa, em termos de relação com o objeto, com a consideração da materialidade das palavras e com a existência material do poema no objeto. Mesmo sendo especulativa, a identificação dessa afinidade funciona esquematicamente para expor as especificidades de Broodthaers em relação à literatura nos museus, ou à própria dissolução de livros, os seus e os dos outros. ${ }^{11}$ No que concerne a herança conquistada pelo artista, existe um vocabulário que estreita as fronteiras entre o readymade, as experiências de Beuys em termos pedagógicos ou de engajamentos, as seriações de Warhol, e o referido vocabulário conduz o artista para um lugar onde o próprio museu é inventado a partir do que pode ser identificado como uma paródia do ato de classificar e colecionar (MACIEL, 2008). Maria Esther Maciel possui uma formulação a partir dos limites da coleção em que o inclassificável, ou seja, aquilo que escapa da coleção, seria o estímulo necessário para que o colecionador persista em ampliar a sua coleção, ampliação que poderia ser traduzida, nesse caso, como uma elaboração de um vocabulário próprio, a partir dos objetos. As coleções e os museus de Broodthaers necessitam dessa formulação para existir, sendo essa a base para suas materialidades

10 Em tradução conjunta com Loïck Lemesle: "Nenhum homem de lei se vangloria de desalojar o intruso - contratos tácitos, usos locais - estabelecido por surpresa e tendo mesmo pago aos proprietários: eu devo representar o papel ou restringir, aos meus direitos, a usurpação".

11 Refiro-me ao estudo de Cadôr (2016).

Remate de Males, Campinas-SP, v. 37 n. 1, pp. 261-284, jan./jun. 2017 
literárias. Assim o silêncio do poeta retorna ao artista depois que seu museu decretou falência: o binômio falha-falência é uma conquista da precisão da linguagem na sua ação mais restrita. A falência do museu equivaleria à "conquista do espaço", isto é, uma interpretação livre dos signos literários reduzidos a um estado mínimo de presença.

As relações econômicas são definidoras para o artista desde o momento em que ele reproduz textualmente a conversa com um galerista sobre a venda de objetos artísticos. Assim, o artista constrói um museu com a falência decretada, e sua assinatura torna-se um símbolo de trânsito entre a poesia e o câmbio monetário. Com a assinatura reduzida às suas iniciais, Broodthaers repete o "M.B." em cursiva em duas telas de 1973, onde se lê, acima na primeira tela, "Gedicht", "Poem", "Poème” e, na segunda, "Change", "Exchange”, "Wechsel" (Figura 4).

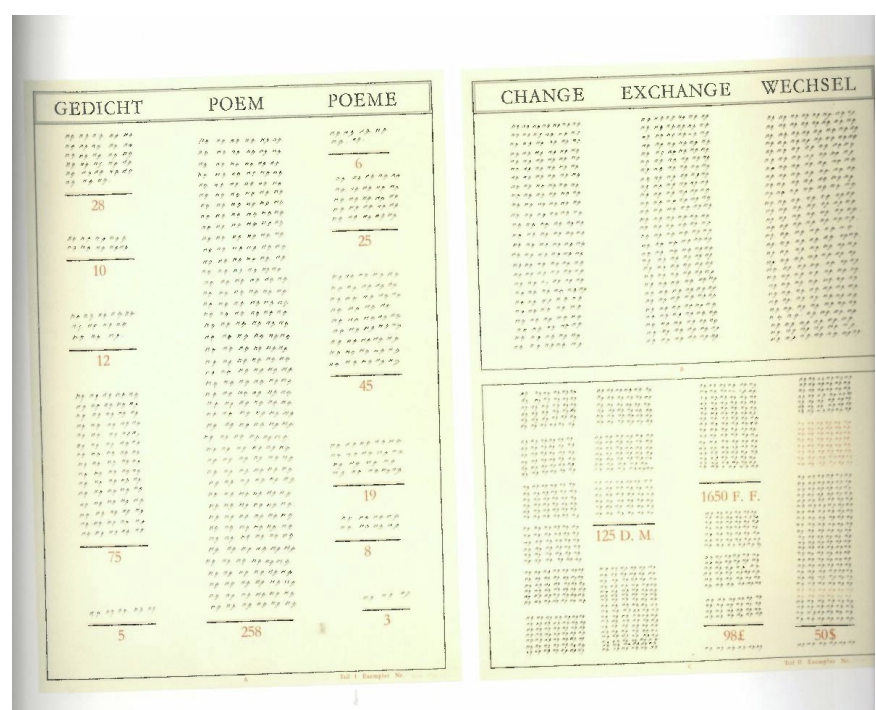

Figura 4. Gedicht poem poème, change exchange wechsel, de Marcel Broodthaers (1973). Fonte: Borja-Villel e Cherix (2016).

Com a escrita e o cálculo o artista atua entre o "poema" e o "câmbio". Anteriormente, entre 1964-1968, ele havia produzido dois objetos em madeira e vidro, que representam a fachada de um banco, nas dimensões: $92 \mathrm{~cm}$ x $300 \mathrm{~cm}$ x $30 \mathrm{~cm}$. No primeiro se lê "Coupons", "Change”, “Ordres de Bourse” e no segundo, "poèmes". Em uma das portas está termo "pérail”, que designa um tipo de queijo vindo da região sudeste da França, Aveyron.

A assinatura do artista elabora uma nova situação, que encaminha como hipótese não mais o abandono do poema, e sim uma operação 
cambial que teria acontecido no espaço de exposição. Ela se refere ao modo como ele quis interpretar textos e autores de sua predileção. Durante esse câmbio - e as obras não apenas testemunham essa duração, mas a sustentam -, a poesia seria para Broodthaers um modo de fazer com que a imaginação atue sobre a coleção, na qual o mistério dos livros fechados, expostos, persistiria no silêncio dos objetos. Até que ponto o poeta se submeteu às próprias ações artísticas? Até que momento tais ações movimentam um poeta silencioso, fazendo, pelo universo das reproduções e de cartões-postais, um "convite à viagem”, tema por excelência baudelairiano? No início dos anos sessenta, sua colaboração para o Journal des Beaux-Arts de Bruxelas era "Un poète en voyage" (2012, p. 55). A cadeia interpretativa dos signos que impregnam os objetos, uma "arte da poesia" [the art of poetry], está anunciada em um dos poemas, que foi coberto por um recorte quadrado vermelho, do livro Pense-bête, na tradução inglesa disponível nos Collected writtings:

The art of poetry

A taste for secrecy and the practice of hermeticism are one and the same, and for me, a favorite game. But here, I want to reveal the sources of my inspiration, this time abandoning all inhibitions.

Legal literature has often aroused my imagination. Here the place of the word is very clear. The ambiguity of the Law is no doubt in the interpretation of the text; in the spirit and not the letter.

In legal statutes, the word shines like a solitaire. Well, this has been my passion since I first learned to read. A dangerous passion, an obsessive one, and among its scant results, these few poems, turned from their nature, from people and from things.

Here is a sample of my bedtime reading

(BROODTHAERS, 2012, p. 102). ${ }^{12}$

12 "Um gosto pelo segredo e um pela prática da hermenêutica foram iguais e idênticos e, para mim, um jogo predileto. Mas aqui, quero revelar as fontes da minha inspiração, dessa vez abandonando todas as inibições. / Doutrinas sempre despertaram minha imaginação. Aqui o lugar da palavra é bem nítido. / A ambiguidade da Lei está, sem dúvida, na interpretação do texto; no pensamento, e não na letra. Nos estatutos legais, a palavra brilha praticamente solitária. Bem, esta foi a minha paixão, a mais obsessiva, e entre seus raros resultados, esses poucos poemas, mudaram sua natureza, do povo e das coisas. / Aqui está uma amostra da minha leitura de cabeceira.” A preferência pelo termo "doutrina" (Legal literature) na tradução é apenas para reforçar algo que pode estar na literatura jurídica, mas também em textos em que a regra e a lei tenham uma relação com a palavra conforme o artista descreve.

Remate de Males, Campinas-SP, v. 37 n. 1, pp. 261-284, jan./jun. 2017 
Em textos doutrinários com um sistema bem definido, embora dependentedeinterpretações, a palavraépassível de ser isolada. A mudança de estatuto passa por "procedimentos legais", isto é, com a palavra isolada, com a chave da interpretação da sua lei mais secreta. Não tendo a poesia as mesmas leis da arte, cabe ao artista utilizar o lugar da fala durante a própria exposição dos seus objetos. Esse é o seu jogo predileto. O lugar da palavra é o espaço da fala, das interpretações possíveis de uma outra lei, a da literatura. Ela possibilita uma hermenêutica do espaço expositivo onde praticamente é à palavra que o artista dedica cada um dos lugares que inventa. Afirmar que o lugar da palavra é o da fala nos ajuda a entender que o artista teve uma visão pictural da oralidade da língua. Dado que é impossível manter o espaço da fala preenchido integralmente pelo som, Broodthaers pontuou visualmente o espaço do silêncio com repetições e vazios de acordo com uma forma literária existente. Ele produz na língua francesa um silêncio pictórico, menos analítico, em que pouco a pouco o escritor ou a assinatura M.B. volta à palavra a partir da terceira pessoa do singular: ele [il]. Il parle [Ele fala], de 1972 (Figura 5).

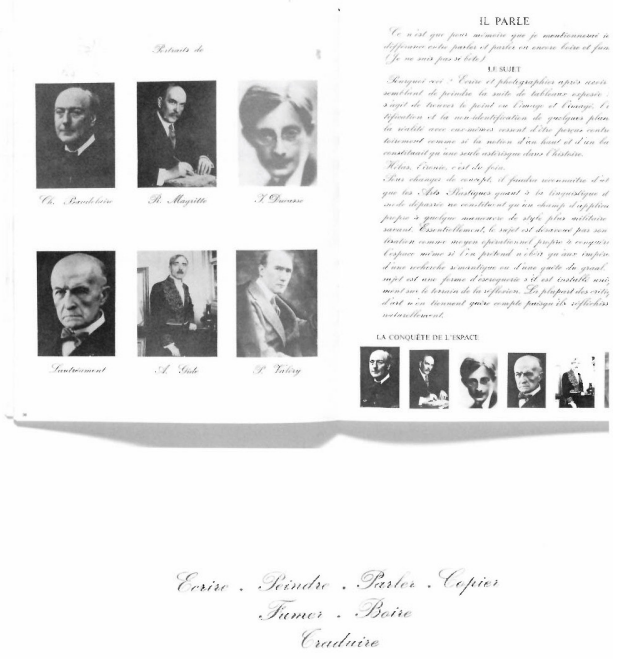

Figura 5. Foto da página onde está impresso o poema "Il parle" (BROODTHAERS, 1972). Fonte: Catálogo (1972, pp. 36-37).

Na obra em questão, os retratos de Paul Valéry, René Magritte, Charles Baudelaire, Isadore Ducasse, Lautréamont e André Gide foram 
trocados e ocupam um espaço diferente dos seus respectivos nomes, nas legendas das fotografias. A palavra "jogo" é importante porque o artista trabalha ludicamente com a memória: "Ce n'est que pour mémoire que je mentionnerai ici la différance entre parler et parler ou encore boire et fummer... (Je ne suis pas si bête)" (BROODTHAERS apud BORJA-VILLEL; CHERIX, 2016, p. 274). ${ }^{13}$ Broodthaers (p. 274) busca um modo de distinguir um estilo que marca a diferença entre falar $e$ falar, como ele escreve ainda no mesmo texto:

Pourquoi ceci ? écrire et photographier après avoir fait semblant de peindre la suite de tableaux exposée ? Il s'agit de trouver le point ou l'image et l'imagé, l'identification et la non-identification de quelques plans de la réalité avec euxmêmes cessent d'être perçus contradictoirement comme si la notion d'un haut et d'un bas ne constituait qu'une seule astérisque dans l'histoire.

Hélas, l'ironie, c'est du foin.

Pour changer de concept, il faudra reconnaitre d'abord que les Arts Plastiques quant à la linguistique d'une mode dépassée ne constituent qu'un champ d'application propre à quelque manœuvre de style plus militaire que savant. Essentiellement, le sujet est désavoué par son utilisation comme moyen opérationnel propre à conquérir de l'espace même si l'on prétend n'obéir qu’aux impératifs d'une recherche sémantique ou d'une quête du graal. Le sujet est une forme d'escroquerie s'il est installé uniquement sur le terrain de la réflexion. La plupart des critiques d'art n'en tiennent guère compte puisqu'ils réfléchissent, naturellement. ${ }^{14}$

O problema do estilo, em Broodthaers, passa de um "como dizer" da literatura, que participa igualmente de uma problemática linguística, para uma precisão alcançada nas artes plásticas, como vista pelo artista como todo o desenvolvimento de uma estratégia que está mais próxima de uma manobra militar. A ironia e, de modo mais amplo, o humor fazem com que a reflexão do artista constitua o seu objetivo - a conquista do espaço - e

13 "Será apenas de memória que mencionarei aqui a diferença entre falar e falar, ou ainda entre beber e fumar... (Eu não sou tão bobo assim)."

14 "Por que isto? escrever e fotografar depois de ter fingido pintar a sequência de quadros exposta? Trata-se de encontrar o ponto ou a imagem e o imaginado, a identificação e a não identificação de alguns planos da realidade com eles próprios, deixando de ser percebidos contraditoriamente como se a noção de um alto e de um baixo constituísse apenas um único asterisco na história. / Infelizmente a ironia não é nada demais. / Para mudar de conceito será preciso reconhecer primeiro que as Artes Plásticas em relação à linguística, de um modo ultrapassado, constituem apenas um campo de aplicação próprio a alguma manobra de estilo mais militar do que erudita. Essencialmente, o sujeito é renegado por sua utilização como meio operacional próprio para conquistar o espaço mesmo, se se pretende apenas obedecer aos imperativos de uma pesquisa semântica ou de uma busca do graal. $\mathrm{O}$ assunto é uma forma de trapaça, se está instalado apenas no terreno da reflexão. A maior parte dos críticos de arte não levam isso em conta, porque refletem, naturalmente."

Remate de Males, Campinas-SP, v. 37 n. 1, pp. 261-284, jan./jun. 2017 
que, entre o pictural e o linguístico, exista um modo de utilizar a realidade da língua criada pelos poetas para evitar ambos, a estratégia militar e a erudição. Para negá-los o artista vive sua obra como um militante da ironia. Isso acontece nos painéis Série en langue française (Série de neuf peintures sur um sujet littéraire) [Série em língua francesa (Série de nove pintores sobre um assunto literário)], de 1972, nos quais Marcel Broodthaers, recuperando sua tradição, mostra em cada um deles, impresso em preto, apenas o nome de cada autor com as respectivas datas de nascimento e de morte, e uma atividade, como fumar, escrever, copiar, pintar, beber; até o último, onde se lê "Il parle" ["ele fala"]. A série se prolonga em uma variação em língua inglesa (Edgar Allan Poe, Lewis Carroll, William Blake, Oscar Wilde, James Joyce, Charles Dogson, Jonathan Swift) e em língua alemã (Kant, Goethe, Beethoven, Hegel, Hölderlin, Marx, Nietzsche). Em "Il parle" a série possui variações como a língua inglesa ou alemã, além disso, no detalhe de outra página do catálogo Actualité d'un bilan, concebido pelo artista, estão catalogadas as seguintes atividades artísticas: escrever, pintar, falar, copiar, fumar, beber, traduzir.

"A diversidade não deixa de me surpreender", escreve Broodthaers (apud BORJA-VILLEL; CHERIX, 2016, p. 278) em um breve poema intitulado "Théorie générale de l'art et de la collection" (Teoria geral da arte e da coleção). Se a conquista do espaço foi amplamente perseguida por ele, a realização de tal conquista implica um uso deliberado de situações de leitura, a começar pelo livro fechado, pelo poema coberto ou escondido, pelas iniciais do seu nome e ainda por imagens retiradas de poemas ou de outras pinturas que se concretizam em elementos da cultura belga, como o mexilhão, o ovo ou as batatas fritas. Os dois primeiros possuem um uso bem amplo na obra de Broodthaers, são repetidos à exaustão até comporem uma camada densa e escura em painéis de mexilhões, por um lado, e, por outro, um acúmulo de cascas de ovos em armários, sobre cadeiras ou mesmo em painéis, gerando diversas tonalidades de branco. Em um dos catálogos, Moules œufs frites pots charbon, de 1966, o artista possui um texto intitulado "Poème" [Poema]:

Tout est œufs. Le monde est œuf. Le monde est né du grande jaune, le soleil. Notre mère, la lune, est écailleuse. En écailles d'œuf pilées, la lune. Poussières d'œuf, les étoiles. Tout, œufs morts et perdus. En dépit des gardes, ce mondesoleil, cette lune, étoiles de trains entiers. Vides. D'œufs vides (BROODTHAERS apud BORJA-VILLEL; CHERIX, 2016, p. 103). ${ }^{15}$

15 "Tudo é ovo. O mundo é ovo. O mundo nasceu de uma grande gema, o sol. Nossa mãe, a lua, é escamosa. Em escamas de ovos empilhados, a lua. Poeiras de ovo, as estrelas. Tudo, 
O poema busca uma conquista do espaço no sentido proposto por Blanchot, odeabandonara Terra. Broodthaers, no entanto, faz uma viagem galáctica a partir da imagem do ovo. Como objeto, este é um elemento recorrente em suas obras, ocupando ilustrações, quadros, instalações com objetos, livros, instalações móveis. A casca do ovo é constantemente explorada pelo artista, mesmo em termos semânticos, como acontece a partir do texto “Poema”. A conquista doespaço, compreendendoa metáfora, a matéria e a metonímia do ovo, faz com que o espaço interior seja cada vez mais enfatizado. Broodthaers põe em prática uma teoria da frase, algo que é literário no sentido de que o modo como ele formula é relevante. Por esse aspecto, Pierre Alferi (2007, p. 13), em três momentos de Chercher une phrase, resume o que pode ser visto como uma materialidade literária: 1) "la littérature met donc en œuvre une théorie de la phrase", 2) "la phrase invente une expérience" (p. 41), 3) "une voix littéraire n'est en ele-même ni blanche, ni douce, ni rugueuse: c'est une voix non vocale" (p. 75). ${ }^{16}$ Os três aspectos podem ser compreendidos em "Poema", "The art of poetry" e "Il parle". O resultado do artista é uma experiência da frase expandida, em que ele consegue abrir o espaço expositivo para criticar a própria arte enquanto "campo de aplicação".

A relação entre o uso de um estilo que conduz a um campo de aplicação e a vida militar é uma descoberta que o conduzirá à produção de uma instalação que reflete sobre o "Décor", na qual se situa um jardim de inverno criado pelo artista, como descreve Cathleen Chaffee (apud BORJA-VILLEL; CHERIX, 2016, p. 290):

In early 1974 Marcel Broodthaers turned a gallery at the Palais des Beaux Arts, Brussels, into a verdant winter garden for a group exhibition. He installed palm trees, folding garden chairs, vitrines, nineteenth-century zoological prints, and photographic enlargements of prints depicting elephants, falcons, camels, bees, and scarabs. A television monitor connected to a live-feed video camera broadcast the scene: the trees, the chairs arranged in a circle, visitors passing by. In the artist's book he published for the occasion, Broodthaers identified this scultural group, Un jardin d'hiver, as a "décor". ${ }^{17}$

ovos mortos e perdidos. Apesar das garantias, esse mundo-sol, essa lua, estrelas de trens inteiros. Vazios. De ovos vazios."

16 Respectivamente: "a literatura realiza uma teoria da frase", "a frase inventa uma experiência”, “uma voz literária não é por si mesma nem branca, nem doce, nem rugosa: é uma voz não vocal".

17 "No início de 1974, Marcel Broodthaers transformou a galeria do Palais des Beaux Arts, em Bruxelas, em um verdejante jardim de inverno para uma exposição coletiva. Ele instalou palmeiras, cadeiras de jardim, vitrines, impressões de zoológicos do século XIX e ampliações fotográficas de impressões descrevendo elefantes, falcões, camelos, abelhas e 
A decoração interior retorna como signo de conforto, de intimidade, de guerra vencida. Ele é o resultado de uma manobra militar bemsucedida, à qual a arte que adorna a sala de estar, tão criticada pelo artista, estaria intimamente ligada. Todas as expansões já imaginadas e realizadas pelo homem, inclusive as que foram feitas no espaço sideral, encontram sua expressão nos detalhes de uma vida confortável no interior da casa, o que Broodthaers chama de "décor" (decoro). Essa expressão última da humanidade está em uma ligação direta com batalhas e guerras, em relação às quais a águia, animal tão emblemático em termos de autoridade, foi para M.B. um momento representativo para dispor em um conjunto a variedade de tal "campo de aplicação".

Sobre el arte contemporâneo, de César Aira (2016), é um dos textos que melhor exprime a relação entre as condições materiais de uma obra de arte, suas técnicas de reprodução e a relação entre ambas diante da fábula que as une. Aira avança a discussão já trazida no texto de Walter Benjamin (200o) sobre a questão da "reprodutibilidade técnica", texto que, por sua vez, tem como epígrafe "La conquête de l'ubiquité", de Paul Valéry, em que o poeta francês convida seu leitor a uma espera das grandes novidades que transformarão toda a técnica das artes. Nesse sentido, o texto de Aira (2016, p. 23) estaria endereçado mais a Paul Valéry do que propriamente a Walter Benjamin:

Si la carrera entre la obra de arte y la reproducción siempre la va a ganar la obra, y la va a ganar, merced al avance de las tecnologías de reproducción, por una ventaja cada vez menor, estamos ante una nueva versión de la competencia de Aquiles y la tortuga. Pero la reproducción, cuando ambas comprenden que lo que importa es la historia, el guion de la fábula, que mueve ambas. ${ }^{18}$

Mesmo que o texto de Benjamin seja uma referência incontornável, a relação Aira-Valéry a partir da reprodutibilidade coincide com o exitoso universo da publicidade, que consegue elaborar uma síntese do sonho e

escaravelhos. Um monitor de televisão conectado a uma câmera de vídeo registra a cena: as árvores, as cadeiras organizadas em círculo, visitantes que passam. Em seu livro, publicado na ocasião, Broodthaers identifica esse conjunto escultural. Um jardim de inverno, como um decoro [décor].”

18 "Se na competição entre a obra de arte e a reprodução sempre a obra vai ganhar, e vai ganhar devido ao avanço das tecnologias de reprodução, por uma vantagem cada vez menor, estamos diante de uma nova versão da competência de Aquiles e a tartaruga. Mas a reprodução, quando ambas compreendem que o que importa é a história, o roteiro da fábula, que move ambas." 
da imagem, participando, inclusive, da construção de sonhos coletivos, como o plano idílico das férias. Aira (2016, p. 23), com certa ironia, expõe a existência concreta das obras de arte, dentre outras coisas, como "anzuelo de turistas" [anzol de turistas].

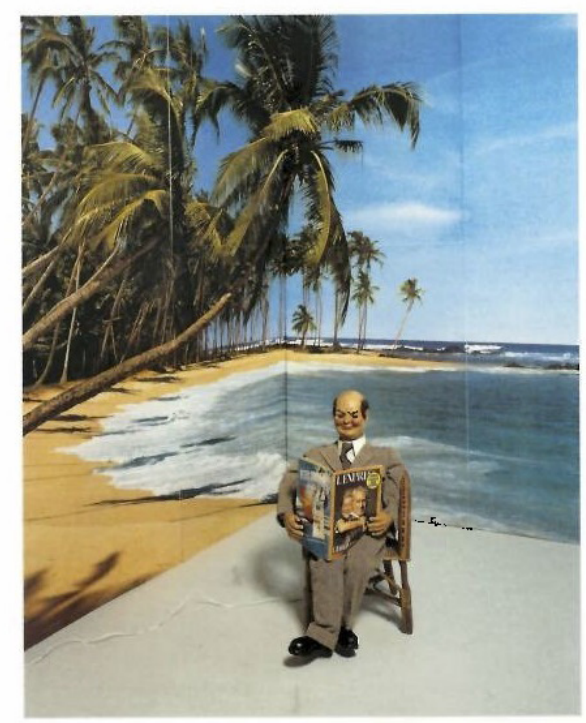

Figura 6. Instalação Monsieur Teste, de Broodthaers (1975). Fonte: Borja-Villel e Cherix (2016).

Para abrir esse "décor", a imagem do Monsieur Teste (Figura 6) feita pelo artista em 1975, reúne o sonho de uma viagem de férias construído com um boneco mecânico de paletó e sentado em uma cadeira de praia. Atrás dele existe a fotografia ampliada de uma praia. Essa é outra possibilidade do decoro, uma imagem desconectada. Para Broodthaers, uma imagem nunca estaria desconectada de outros textos e de outras imagens, pois afinal ela é um elemento de ligação entre textos e outras imagens, parte de um componente que o artista denominou museu. Isso chama a atenção para uma prática de mobilização das palavras em que o museu do artista pode entrar em acordo ou dissentir do museu como instituição. Nas suas estratégias associativas, no modo como ele fragmentava e montava o que lhe interessava de obras literárias, de fotografias de família, o artista estabeleceu uma mitologia para os museus. E um museu para seus poetas, advindo da própria materialidade produzida por eles. Se conseguiu vencer uma batalha contra os gestos museificados, contra a retórica das leis, 
incluindo as literárias e artísticas, talvez o próprio Monsieur Teste, um M. suplementar para Marcel Broodthaers, possa apontar, como Mallarmé, o seu esforço, que ocasionou a produção de tais materialidades literárias: "Il s'agit de passer de zero à zero. - Et c'est la vie. - De l'inconscient et insensible à l'inconscient et insensible" (VALERY, 2014, p. 129). ${ }^{19}$ Provavelmente apenas com seus poemas em livro e, com uma circulação restrita entre seus pares, ele não teria feito tamanho esforço para passar do zero ao zero.

\section{REFERÊNCIAS BIBLIOGRÁFICAS}

AIRA, César. Sobre el arte contemporaneo. Madrid: Literatura Random House, 2016.

ALFERI, Pierre. Chercher une phrase. Paris: Christian Bourgois, 2007.

ANTOINE, Jean-Philippe. Marcel Broodthaers - moule, muse, méduse. Paris: Les Presses du Réel, 2006. (Collection L'espace littéraire)

BENJAMIN, Walter. L'œuvre d'art à l'époque de sa reproductibilité technique. Euvres III. Paris: Folio, 2000, pp. 269-316.

BEZZOLA, Tobia \& KURZMEYER, Roman (orgs.). Harald Szeemann with by Through because Towards Despite (Catalogue of all Exhibitions). Zürich: Voldemeer / New York: Springer Wien, 2007.

BLANCHOT, Maurice. La conquête de l'espace. In: Écrits politiques (1953-1993). Paris: Gallimard, 2008, pp. 125-128.

BORJA-VILLEL, Manuel \& CHERIX, Christophe. Marcel Broodthaers. A retrospective. New York: The Museum of Modern Art, 2016.

BROODTHAERS, Marcel. Pense-bête. 1964. 1 escultura com livros, papel, gesso e bolas de plástico em base de madeira, 30 × 84,5 × $43 \mathrm{~cm}$.

BROODTHAERS, Marcel. Le corbeau et le renard. 1968. 1 serigrafia sobre tela, máquina de datilografar e três serigrafias, $112,5 \times 82 \times 41 \mathrm{~cm}$. Coleção do Centre Georges Pompidou, Paris.

BROODTHAERS, Marcel. Un coup de dés jamais quand bien même. 1969. 1 pintura em tela, $165 \times 122 \mathrm{~cm}$.

BROODTHAERS, Marcel. Série en langue française (Série de neuf peintures sur um sujet littéraire). 1972. 9 painéis, 81 x $100 \mathrm{~cm}$ (cada).

19 “Trata-se de passar do zero ao zero - E é a vida - Do inconsciente e insensível ao inconsciente e insensível."

Remate de Males, Campinas-SP, v. 37 n. 1, pp. 261-284, jan./jun. 2017 
BROODTHAERS, Marcel. Gedicht poem poème, change exchange wechsel. 1973. 2 telas em serigrafia, 97,8 cm x 68,1 cm (cada).

BROODTHAERS, Marcel. Monsieur Teste. 1975. 1 instalação contendo figura mecânica, cadeira de palha, revista e backdrop cênico, dimensões variadas.

BROODTHAERS, Marcel. Collected writings. Organizado por Gloria Moure. Barcelona: Poligrafa, 2012.

BUCHLOH, Benjamin. First and Last: Two Books by Marcel Broodthaers. In: BORJAVILLEL, Manuel \& CHERIX, Christophe. Marcel Broodthaers. A retrospective. New York: The Museum of Modern Art, 2016, pp. 40-49.

CADÔR, Amir Brito. O livro de artista e a enciclopédia visual. Belo Horizonte: Editora da UFMG, 2016.

DUCHAMP, Marcel. Rrose Sélavy. Oculisme de précision. New York/Paris: G.L.M, 1939.

ELIOT, T.S. Tradition and the Individual Talent. Perspecta, New York, v. 19, 1982, pp. 36-42.

CATÁLOGO Actualité d'un bilan. Paris: Yvon Lambert, 1972.

MACIEL, Maria Esther. Poéticas do inclassificável. Revista Aletria (Poslit-UFMG), v. 15, 2008, pp. 155-162.

MALLARMÉ, Stéphane. Variations sur un sujet. In: . Euvres complètes. Paris: Gallimard, 1945, pp. 355-368.

MARX, William. L'adieu à la littérature. Histoire d'une dévalorisation XVII ${ }^{e}-X X^{e}$ siècle. Paris: Les Éditions de Minuit, 2005.

O’DOERTY, Brian. No interior do cubo branco. Trad. Carlos Mendes Rosa. São Paulo: Martins Fontes, 2002.

RANCIÈRE, Jacques. L'espace des mots: de Mallarmé à Broodthaers. Nantes: Musée des Beaux-Arts de Nantes, 2005.

VALÉRY, Paul. Monsieur Teste. Paris: Gallimard, 2014. 